\title{
Planning Nervousness in Product Segmentation: Literature Review and Research Agenda
}

\author{
Ann-Louise Andersen, Nicolai Præstholm, Kjeld Nielsen, and Thomas Ditlev Brunø \\ Department of Mechanical and Manufacturing Engineering, \\ Aalborg University, Denmark \\ annlou. andersen@gmail.com
}

\begin{abstract}
Differentiated planning is one of the means for today's companies to accommodate the increasing needs for product variety, delivery responsiveness, and cost-efficiency. Even though, product segmentation is the foundation for such planning, planning nervousness has not yet been addressed from this perspective. This paper seeks to establish a relation between planning nervousness and segmentation by analyzing the current body of literature with the objective of identifying overlaps between the two areas. The literature characteristics are assessed and directions for future research are provided.
\end{abstract}

Keywords: Planning, Nervousness, Product Segmentation.

\section{Introduction}

In today's business environment, one of the means to achieving competitive advantage is to offer a wide range of differentiated products in a cost-efficient and responsive manner, as customers have increasingly different needs [1]. As a result, companies need to design supply chains that can cope with conflicting demand, e.g. the need for providing both low-cost and customized product solutions, which means that supply chains must operate different setups simultaneously. The key to this is differentiated planning and control, where products are assigned to relevant product segments, which are subject to different planning methods, e.g. make-to-stock or make-to-order. The underlying foundation for practicing differentiated planning is the segmentation of products and items flowing in the supply chain. When this process is managed properly, a stable basis for securing product and item availability at the right levels of inventories is secured. In contrary, if the segmentation process contains instability, uncertainty is likely to ramify throughout the supply chain and through planning levels.

Thus, the purpose of this paper is to identify current state-of-art knowledge and unravel critical points on planning nervousness, in order to identify possible relations to item segmentation that can broaden knowledge of how to manage uncertainty in differentiated planning. 


\section{Literature Review Methodology}

The objective of this literature review is to identify major tendencies in current literature on planning nervousness and possible connections to segmentation. Relevant research concerning nervousness was identified by searching the Web of Knowledge, Science Direct, Scopus, and Google Scholar databases. In order to ensure that relevant studies were not missed, four rather broad search terms were used: nervousness, planning nervousness, scheduling nervousness, and re-scheduling. Publications for the review were included if a) the study included one of the search terms in the title or abstract and if b) planning nervousness was included as a central element in the research. Through a qualitative assessment of these criteria, studies that primarily use nervousness as a term for uncertainty in general was excluded, as well as studies in which a specified planning level was not the primary context for the research or planning nervousness was only a minor parameter addressed. A total of 21 publications from 1979 to present were included and used as primary research in the review. In the following section, a brief review of the concept of planning nervousness is presented, followed by an assessment of the nervousness influencers that have been identified in literature.

\section{$3 \quad$ Planning Nervousness}

Planning nervousness is a term that has existed in research since the late 70's and was initially established for describing instability of plans on MRP level. MRP nervousness is defined as instability and frequent rescheduling of orders in terms of timing and quantity [2] [3] [4]. Later studies extend the concept of nervousness to MPS level, highlighting that nervousness propagates in the planning hierarchy [5] [6] [7]. Most recently, the concept of planning nervousness is broadened and covers multiple planning levels as well as multiple entities within supply chains [8] [9] [10]. In this sense, planning nervousness can be defined as the counterpart to planning stability, which is defined as the situation where plans do not change and equal the actual requirements imposed on the system [11]. Moreover, recent studies point out that nervousness has both vertical propagation in the planning hierarchy and horizontal propagation within the supply chain, which makes the phenomena highly critical to multiple performance aspects [12] [9] [13]. In connection to this, planning or system nervousness can be defined as a specific planning performance parameter, which magnitude should be evaluated when determining planning policy, e.g. inventory control policy or lot size policy [14] [15] [16].

Nervousness can be described as a consequence of planning flexibility and the ability to continuously respond to changing customer requests, where an essential trade-off between responsiveness and nervousness exists [17] [18]. However, this trade-off is primarily dealt with in the discussion of how often to re-plan, where frequent re-planning results in more updated parameters and ability to respond to urgent and changing customer needs, while nervousness increases in relation to the transition from the original plan to the updated plan. This relation emphasizes that 
planning nervousness cannot be approached in a vacuum, as it is a direct consequence of the applied planning policy and decisions within the planning system and therefore is interrelated with other planning outcomes e.g. service, responsiveness, and cost.

As the definition of planning nervousness has broadened, so has the discussion of its impact. In early works the consequence of MRP nervousness is primarily described as being confusion in shop floor priority, fluctuations in capacity utilization and incurring high rescheduling cost [19]. However, gradually the outcome of nervousness has been related more and more to the bullwhip effect, resulting in the two phenomena being used virtually as synonyms [9] [10] [12]. The bullwhip effect can basically be described as demand amplifications throughout the supply chain, where upstream links experience more fluctuating demand than downstream links, even when actual sales is rather stable [20]. The results of this are increased inventory buffers throughout the chain, fluctuating inventory levels, low capacity utilization, and delivery problems [12]. The similarities with nervousness are evident, as both the bullwhip effect and planning nervousness result from uncertainty generated by actions and policies applied within the planning system. However, when relating planning nervousness and the bullwhip effect, only the horizontal propagation of nervousness is considered, even though planning nervousness propagates both horizontally in the supply chain and vertically through planning hierarchies and product structure levels [10] [12]. Therefore, planning nervousness is in this paper considered as the broadest applicable term for system and planning uncertainty, defined as instability of plans in terms of timing and quantities requiring frequent rescheduling activities.

Some of the currently most addressed consequences of planning nervousness are disruptions in production plans and deliveries, increased inventory buffers, and increased planning cost [19] [11] [12]. Moreover, as plans become more and more unstable and predictability decreases, both planners and operators have reduced confidence in the planning system [2]. When the planning system does not reflect actual requirements on the operating system, humans are compelled to make manual adjustments in order not to damage customer service. However, such human planning adjustments and manipulations have actually proved to reinforce rather than mitigate planning nervousness, which creates a vicious circle of increased nervousness [10].

\section{$4 \quad$ Planning Nervousness Influencers}

Planning nervousness is addressed in various different planning contexts, which implies that various different influencers of nervousness are addressed as well. In Table 1, nervousness influencers addressed in central research are listed and divided as being either operational or environmental. The operational variables are directly controllable as they are internally generated and can be managed through planning policies, while the environmental variables are set by the operating environment and incontrollable by the planning system [19]. Some of the influencers included here are discussed primarily as means to dampen nervousness in the specific papers. However, recognizing a variable's dampening effect on nervousness is highly related to recognizing it as an influencer on nervousness. 
In Figure 1, the influencers are classified under relevant groups that cover the meaning of the specifically mentioned influencers in Table 1 . The aim of this is to unravel critical points in current knowledge and identify potential connection with product segmentation. In line with this, the findings suggest that there are currently two major tendencies in nervousness literature. The first is the discussion of how demand uncertainty and demand characteristics, e.g. in the timing and quantity of orders, influence the degree of nervousness experienced in the planning system. However, despite the inevitable impact of demand uncertainty, research in this area focuses solely on parameters that are difficult to control by companies. The second tendency in nervousness literature is the discussion of the impact of planning horizon, planning frequency, and lot-sizing rules on planning nervousness. The great main part of current research focuses on these parameters in inventory or MRP contexts. Despite the relevancy of such research, it has limited relevancy to product segmentation processes, where nervousness is believed to have as severe consequences as in the already treated planning contexts.

Table 1. Overview of Nervousness Literature

\begin{tabular}{|c|c|c|c|}
\hline & Operating Variables & Environmental Variables & Context \\
\hline [2] & Lot-sizing, planning horizon & & MRP \\
\hline [15] & Lot-sizing, order releases & Demand Variability & MRP/LRP \\
\hline [4] & $\begin{array}{l}\text { Planning frequency, planning horizon, } \\
\text { lot-sizing }\end{array}$ & $\begin{array}{l}\text { Demand Uncertainty } \\
\text { Cost Structure }\end{array}$ & MRP \\
\hline $\begin{array}{l}{[21]} \\
{[22]}\end{array}$ & $\begin{array}{l}\text { Rolling horizon (planning frequency } \\
\text { and planning horizon), lot-sizing, } \\
\text { reordering method }\end{array}$ & & $\begin{array}{l}\text { Inventory } \\
\text { Control }\end{array}$ \\
\hline [19] & $\begin{array}{l}\text { Lot-sizing, length of lead-time, length } \\
\text { of planning horizon, component } \\
\text { commonality }\end{array}$ & $\begin{array}{l}\text { Demand variability, capacity } \\
\text { utilization, cost structure in } \\
\text { regards to delivery performance }\end{array}$ & MRP \\
\hline $\begin{array}{l}{[12]} \\
{[23]}\end{array}$ & $\begin{array}{l}\text { Planning horizon, planning frequency, } \\
\text { varying planning processes }\end{array}$ & $\begin{array}{l}\text { Demand variability, supply } \\
\text { chain integration/collaboration, } \\
\text { delay in information flow }\end{array}$ & $\begin{array}{l}\text { Supply } \\
\text { chain } \\
\text { planning }\end{array}$ \\
\hline $\begin{array}{l}{[9]} \\
{[10]}\end{array}$ & $\begin{array}{l}\text { Planning Frequency, ease of } \\
\text { representation (e.g. complexity of } \\
\text { planning system), } \\
\text { intervention/adjustments made by } \\
\text { human planners, planning horizon }\end{array}$ & $\begin{array}{l}\text { Number and structure of } \\
\text { (organizations) planning levels, } \\
\text { planning inertia (e.g. time to } \\
\text { react), degree of interrelations } \\
\text { in planning system }\end{array}$ & $\begin{array}{l}\text { Planning } \\
\text { hierarchy }\end{array}$ \\
\hline [11] & & $\begin{array}{l}\text { Changes in customer orders, } \\
\text { availability of raw materials, } \\
\text { capacity/production uncertainty }\end{array}$ & MPS \\
\hline $\begin{array}{l}{[7]} \\
{[6]}\end{array}$ & $\begin{array}{l}\text { Length of planning horizon, length of } \\
\text { frozen schedule, re-planning frequency, } \\
\text { non-frozen interval strategy }\end{array}$ & $\begin{array}{l}\text { Natural order cycle length, } \\
\text { vendor flexibility, demand } \\
\text { range, demand lumpiness }\end{array}$ & MPS \\
\hline
\end{tabular}




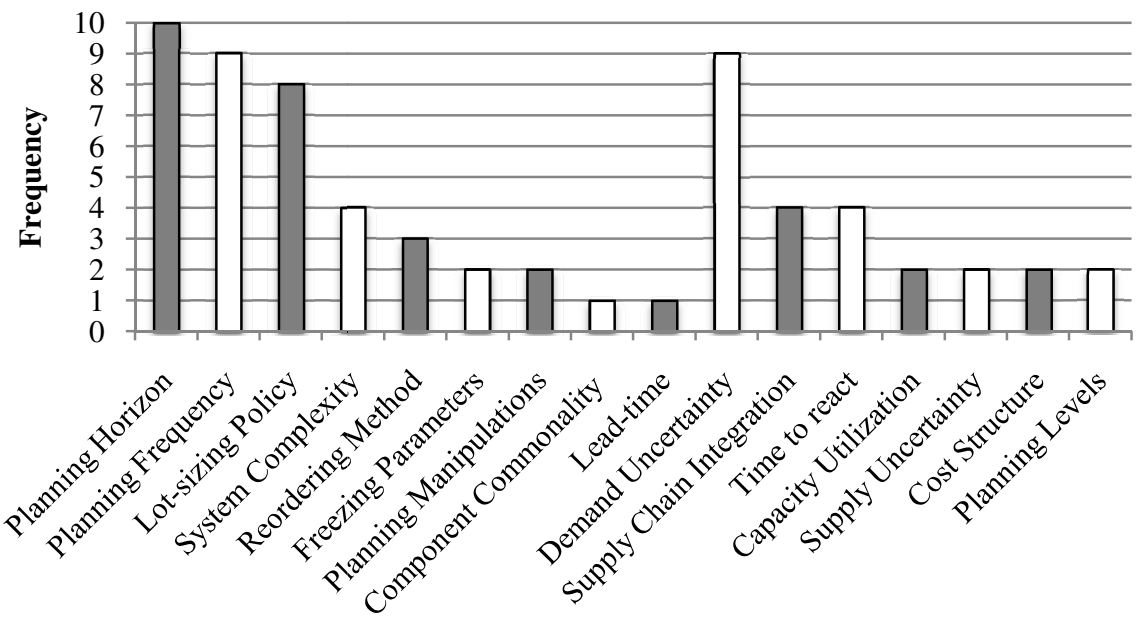

Fig. 1. Grouping of Nervousness Influencers

From the literature discussed above, it can be concluded that planning nervousness has received only limited attention in literature even though the term has existed for more than three decades. Moreover, research is limited to specific contexts, even though planning nervousness is considered a relevant property of planning system in general and undoubtedly has severe consequences in planning contexts other than those already addressed in literature. This also indicates a lack of explicit connection between planning nervousness and product segmentation.

The lack of connection between the two areas is critical, as product segmentation is an underlying process that secures a solid foundation for various planning activities both within single companies and integrated supply chains. Determining whether products are make-to-order or make-to-stock highly impacts how products are planned, replenished, and controlled. As nervousness propagates throughout planning levels, it is important to assess how this segmentation process impacts planning stability throughout the entire system. As in inventory management systems, where nervousness already has been well-addressed and quantified, decisions within the segmentation process and their impact on planning nervousness need to be assessable and measurable as well. This will constitute a highly improved foundation for decision-making, rather than merely relying on subjective intuition when addressing and handling nervousness issues in companies.

\section{$5 \quad$ Nervousness in Product Segmentation}

In order to broaden the context of planning nervousness and establish a connection with product segmentation, the definition, causes, and consequences of nervousness needs to be assessed from a segmentation context, as this will increase the 
operationalization of the nervousness concept. In the following, tentative connections between the two areas are proposed, which indicate future research directions as well.

In terms of defining segmentation nervousness, the trade-off between planning nervousness and responsiveness applies, as it is not related to a specific planning level or context. In this definition, nervousness is essentially planning uncertainty and shocks created by shifts and changes in plans, while responsiveness covers the ability to reflect the reality and react timely to changes in the requirements imposed on the system.

Thus, in the context of segmentation, nervousness can be defined as shifts in the assigned groups for specific products, while responsiveness relates to immediately and continuously updated segmentations based on changes in segmentation criteria e.g. demand variability, demand volume, etc. With this definition, planning nervousness in the context of segmentation is directly assessable, as it can be quantified by the number of shifts made in the segmentation between to successive runs. As a result, planning nervousness can be approached as a parameter under planning performance. It is a topic for further research, to investigate and empirically test if this relation between nervousness and segmentation holds. Moreover, studying the exact consequences of nervousness in segmentation should be on future research agendas, as literature on neither nervousness nor segmentation explicitly addresses this issue. It is expected that segmentation nervousness has both direct consequences as well as ramifications to other planning levels. A direct consequence is that stocking strategies for specific products change frequently, which causes either excess inventories or material unavailability. Olhager [24] describes both the negative and positive effects of shifting customer-order-decoupling point (CODP), which is related to the overall segmentation. However, he discusses CODP shifts solely from the perspective of strategic positioning and not from the perspective of frequent shifting caused by the planning processes. The strategic CODP shift effects are reduced or prolonged lead-times, increased or decreased production efficiency, and reduction or increases in WIP and inventory levels. In the context of frequent shifting, uncertainty in all of these areas is expected, which should be subject to further research.

In the literature review, rolling horizons were identified as one of the major sources of planning nervousness. The rolling horizon can be assessed through planning frequency and planning horizon, which are directly controllable parameters within the planning system. As the impact of these is highly acknowledged and they are both directly related to how segmentations are carried out, investigating their impact on nervousness is considered a viable first step in making a quantitative connection between the two areas. This will constitute a useful quantification and operationalization of key segmentation parameters in relation to planning nervousness.

\section{Conclusion}

Even though planning nervousness has existed as a research term for more than three decades, it is still limited to a few research contexts, being primarily MRP and 
inventory systems. However, planning nervousness is a relevant attribute of planning performance in general, meaning that other planning contexts should be considered in relation to nervousness as well.

In this paper, attention is drawn to the area of differentiated planning where a theoretical and tentative relationship to planning nervousness is established. The importance of such relation is based on the notion that companies are required to offer an increased variety of products, where differentiated planning and control is the key in terms of operating different supply chain setups simultaneously. Currently, there is no explicit connection between the two areas, which has two consequences. First of all, with no directly assessable connection, companies have to rely on subjective intuition when battling nervousness in planning systems. Secondly, as the connection between nervousness and segmentation is currently not emphasized sufficiently in research, companies are likely to treat symptoms rather than the root causes of nervousness, as nervousness ramifies through planning levels where segmentation is the overall differentiated planning foundation. Therefore, a quantification and verification of the relationship between nervousness and item segmentation should be subject to further research.

\section{References}

1. Fisher, M.: What is the right supply chain for your product? Harvard Business Review (March-April 1997)

2. Blackburn, J., Kropp, D.H., Millen, R.A.: A comparison of strategies to dampen nervousness in MRP systems. Management Science 32(4), 413-429 (1986)

3. Minifie, J.R., Davis, R.A.: Interaction effects on MRP nervousness. International Journal of Production Resources 28, 173-183 (1990)

4. Carlson, R.C., Jucker, J.V., Kropp, D.H.: Less nervous MRP systems: a dynamic economic lot-sizing approach. Management Science 25(8), 754-761 (1979)

5. Sridharan, V., Lawrence LaForge, R.: The Impact of Safety Stock on Schedule Instability, Cost and Service. Journal of Operations Management 8(4) (1989)

6. Robinson Jr, P., Sahin, F., Gao, L.-L.: Master production schedule time interval strategies in make-to-order supply chains. International Journal of Production Research 46(7) (2008)

7. Sahin, F., Powell Robinson, E., Gao, L.-L.: Master production scheduling policy and rolling schedules in a two-stage make-to-order supply chain. International Journal of Production Economics 115, 528-541 (2008)

8. Genin, P., Lamouri, S., Thomas, A.: Improving the robustness of a supply chain tactical plan. Supply Chain Forum 8(2) (2007)

9. Moscoso, P.G., Fransoo, J.C., Fischer, D.: An empirical study on reducing planning instability in hierarchical planning systems. Production Planning \& Control 21(4), 413426 (2010)

10. Moscoso, P.G., Fransoo, J.G., Fischer, D., Wäfler, T.: The Planning Bullwhip: A Complex Dynmaic Phenomenon in Hierarchical Systems, pp. 159-186 (2011)

11. Pujawan, N.: Schedule nervousness in a manufacturing system: a case study. Production Planning \& Control 15(5), 515-524 (2004)

12. Kaipia, R., Korhonen, H., Hartiala, H.: Planning nervousness in a demand supply network: an empirical study. The International Journal of Logistics Management 17(1), 95-113 (2006) 
13. Tunc, H., Kilic, O.A., Tarim, A.S., Eskioglu, B.: A simple approach for assessing the cost of system nervousness. International Journal of Production Economics 141, 619-625 (2013)

14. Jonsson, P., Mattsson, S.-A.: Inventory management practices and their implications on perceived planning performance. International Journal of Production Research 46(7), 1787-1812 (2008)

15. van Donselaar, K.H., Gubbels, B.J.: How to release orders in order to minimize system inventory and system nervousness? International Journal of Production Economics 78, 335-343 (2002)

16. Kazan, O., Nagi, R., Rump, C.M.: New lot-sizing formulations for less nervous production schedules. Computer \& Operations Research 27(13), 1325-1345 (2000)

17. Schönberger, J., Kopfer, H.: Schedule Nervousness Reduction in Transport Re-Planning, http: //www.sfb637.uni-bremen. de/pubdb/repository/ SFB637-B7-08-004-IJ.pdf

18. Ganeshan, R., Boone, T., Stenger, A.J.: The impact of inventory and flow planning parameters on supply chain performance: An exploratory study. International Journal of Production Economics 71, 111-118 (2001)

19. Ho, C.-J.: Evaluating the impact of operating environments on MRP system nervousness. International Journal of Production Resources 27(7), 1115-1135 (1989)

20. Lee, H.L., Padmanabhan, V., Whang, S.: The bullwhip effect in supply chains. Sloan Management Review 38(7), 93-102 (1997)

21. Inderfurth, K.: Nervousness in inventory control: analytical results. OR Spektrum 16, 113123 (1994)

22. de Kok, T., Inderfurth, K.: Nervousness in inventory management: Comparison of basic control rules. European Journal of Operational Research 103, 55-82 (1997)

23. Kaipia, R.: Coordinating material and information flows with supply chain planning. The International Journal of Logistics Management 20(1), 144-162 (2009)

24. Olhager, J.: Strategic positioning of the order penetration point. International Journal of Production Economics 85, 319-329 (2003) 